\title{
Translation, adaptation and initial validation of Food Allergy Quality of Life Questionnaire: child form in Greek
}

\author{
Zoe Morou, ${ }^{1}$ Georgios N. Lyrakos, ${ }^{2}$ Nikolaos G. Papadopoulos, ${ }^{3}$ Nikolaos Douladiris, ${ }^{3}$ \\ Athina Tatsioni, ${ }^{4,5}$ loannis D.K. Dimoliatis ${ }^{1}$ \\ ${ }^{1}$ Department of Hygiene and Epidemiology, University of loannina Medical School, \\ loannina, Greece; '2Second Department of Anesthesiology, University of Athens Medical \\ School, Athens, Greece; ${ }^{3}$ Allergy Department, 2nd Pediatric Clinic, University of Athens, \\ Greece; ${ }^{4}$ Tufts University School of Medicine, Boston, MA, USA; ${ }^{5}$ Department of Internal \\ Medicine, University of Ioannina Medical School, Ioannina Greece
}

\begin{abstract}
The aim of the study is to determine the reliability and validity of the Greek version of the Food Allergy Quality of life QuestionnaireChild Form (FAQLQ-CF). After linguistic validation, the Greek FAQLQCF, Food Allergy Independent Measure (FAIM) and Pediatric Quality of Life Inventory (PedsQL ${ }^{\mathrm{TM}}$ ) were used by a physician to interview children diagnosed with food allergy and aged 8-12 via telephone. Cronbach's alpha was used to evaluate reliability, and factor analysis to assess construct validity. The correlation between FAQLQ-CF and FAIM was moderate $(\mathrm{rho}=0.509, \mathrm{P}<0.001$ ) and internal consistency was strong (Cronbach's alpha 0.905). FAQLQ-CF discriminated well each question's contribution to children's quality of life deterioration (32-
\end{abstract}

Correspondence: Ioannis Dimoliatis, Department of Hygiene and Epidemiology, University of Ioannina School of Medicine, Ioannina 45110, Greece.

E-mail: idimolia@uoi.gr

Key words: Child; food hypersensitivity; quality of life; questionnaires; validation.

Acknowledgements: Authors are grateful to Katerina Lagara and Spiros Potamianos for conducting the forward and back translation; and to our reviewers for their constructive comments that made our work better.

Contributions: All authors participated in the design of the study. ZM, GL, ID and NP contributed in questionnaire translation; ZM collected the data. GL and ID were responsible for all the data analyses. ZM, GL and ID wrote the manuscript and it was critically reviewed by the other authors. All authors approved the final version.

Conflict of interest: the authors declare no potential conflict of interest.

Received for publication: 27 July 2014.

Revision received: 12 November 2015.

Accepted for publication: 5 February 2016.

This work is licensed under a Creative Commons AttributionNonCommercial 4.0 International License (CC BY-NC 4.0).

(C) Copyright Z. Morou et al., 2016

Licensee PAGEPress, Italy

Health Psychology Research 2016; 4:4624

doi:10.4081/hpr.2016.4624
$80 \%)$, each child's quality of life (17-89\%), children differing in doing things with others (total score 3.55 vs 2.57 , difference $=0.98>$ minimal clinical importance difference $=0.5 ; \mathrm{P}<0.001$ ), but not children differing in reporting anaphylaxis. The total FAQLQ-CF score correlated with the total PedsQL ${ }^{\mathrm{TM}}$ score and with the score of one of PedsQL ${ }^{\mathrm{TM}}$ subscales, demonstrating convergent validity. Factor analysis uncovered an underlying structure of four factors, explaining $50 \%$ of the variance. We can conclude that Greek FAQLQ-CF is a reliable, valid, discriminant tool for interviewing food allergic children aged 812 , detecting those in need for immediate care.

\section{Introduction}

Food allergy in children may be a major global public health problem due to the increasing rate of prevalence (Rona et al., 2007; Mills et al., 2007; Gupta et al., 2011). The upward trend has led the scientific community on an ongoing investigation into the causes, prevention, diagnosis and methods of treatment. The quality of life of children with food allergy disturbed but the exact impact is not adequately specified. Quality of life (QoL) as defined by the World Health Organization (WHO) is the individual's perception of their position in life in the context of the culture and value systems in which they live and in relation to their goals, expectations, standards and concerns (WHO, 1993). Health related quality of life (HRQL) in food allergic children has been assessed by both generic and specific questionnaires. Generic HRQL questionnaires compare patients with the normal population or patients with different diseases, but they are not sensitive to assess specific problems and cannot separate the impact on HRQL of the disease in question from the impact of comorbid diseases (Flokstra-de Blok \& Dubois, 2009; Flokstra-De Blok et al., 2010). Disease specific HRQL instruments are considered more sensitive than the generic ones because they focus on domains most relevant to the disease; they detect clinically important changes in patient's HRQL and they are used as an outcome measure (Flokstra-de Blok \& Dubois, 2009). But, on the other hand, they cannot compare HRQL of patients with different diseases (Guyatt, Feeny, \& Patrick, 1993). The importance of asking children themselves about their own QoL is that children and parents differ in their views, expectations and judgments about children's QoL (van Der Velde et al., 2011). Self-report disease specific questionnaires allow children to report on their own HRQL, contribute to QoL improvement and to holistic treatment.

As part of the EuroPrevall project, a large European multicenter study on food allergy, a series of HRQL questionnaires for food allergic patients of all ages were developed and validated, named the Food 
Allergy Quality of Life Questionnaires (FAQLQ) (Flokstra-de Blok \& Dubois, 2012). The self-report disease specific FAQLQ - Child Form (FAQLQ-CF), completed by children aged 8-12 years, measures changes in HRQL over time, compares children's receiving different treatments HRQL, and assesses several interventions effectiveness (Factor, Mendelson, Lee, Nouman, \& Lester, 2012; Flokstra-de Blok et al., 2009; van Der Velde et al., 2012). Developed in Dutch, the FAQLQ-CF had an excellent internal consistency (Cronbach's alpha 0.94), consists of 24 negative (i.e. higher scores indicate poorer HRQL) items scored 0 to 6 , divided into four subscales: allergen avoidance (AA), risk of accidental exposure (RAE), emotional impact (EI) and dietary restrictions (DR), significantly $(\mathrm{P}<0.001)$ correlated with the Food Allergy Independent Measure (FAIM), a tool for cross-sectional validation on whether the FAQLQs measure what they are supposed to measure at one point in time (Flokstra-De Blok et al., 2009; 2010; Flokstra-de Blok \& Dubois, 2012; Wassenberg et al., 2011; Wassenberg et al., 2012) .

FAQLQ-CF has been validated in English and French. The aim of this study was to translate it into Greek language and explore its psychometric properties.

\section{Materials and Methods}

\section{Participants}

Out of 172 physician-diagnosed food allergic children, followed-up by the Allergy Department of P\&A Kyriakou Children Hospital, a national reference center serving the Athens metropolitan area, all southern Greece and the islands, 110 participated in a telephone survey (64\%), aged 7.5-12.3 years [mean (SD) 10.0 (1.4)], 83 (75.5\%) male, 27 (24.5\%) female. All types of food allergy at different severity and symptom's appearance were present (Supplementary Table S1).

Children with any other major chronic illness (excluding asthma, hay fever or eczema) were excluded. The data were telephone collected by ZM, during 9 May to 3 June 2013. In order to prevent any impact of external factors on children's emotional domain, they were interviewed at a time out of school stressing program while interview process was kept as short as possible. A pilot study including nine of those children addressed some understanding difficulties. During the phone interview, no developmental or maturation differences were observed across the age range we sampled that might impact the results.

\section{Ethical approval}

The Scientific Committee of P\&A Kyriakou Children Hospital approved the study protocol. Parents and children received written information, indicating that participation in the study was voluntary and the telephone interview was conducted after parents and their children acceptance to participate in the study.

\section{Measures}

The disease-specific FAQLQ-CF, the validated in Greek generic Pediatric QoL Inventory ${ }^{\mathrm{TM}} 4.0$ (PedsQL $^{\mathrm{TM}}$ ), and the Food Allergy Independent Measure (FAIM) were used (Gkoltsiou et al., 2008; van Der Velde et al., 2012; Varni, Seid \& Kurtin, 2001). FAQLQ-CF properties were described in the Introduction. PedsQL $\mathrm{L}^{\mathrm{TM}}$ is a 23 -item selfreport measure, divided into 4 subscales: physical functioning, emotions, social relationships, and school functioning, rated on a 5-point Likert scale, and asking about quality of life during the past month (Varni, Seid \& Kurtin, 2001). The Greek version was found to be valid with good internal consistency (only the physical functioning subscale had a Cronbach's $\alpha$ of 0.65 , slightly below 0.70 ; see validation second paragraph, how to interpret these values) (Gkoltsiou et al., 2008).
Higher scores indicate better HRQL. FAIM is a self-report food allergy specific independent measure for children and consists of six questions scored 0 to 6 . The four of them assess child's food allergy expectation outcomes, and the other two reflect aspects of the perceived severity of food allergy. Higher scores indicate poorer HRQL. A moderate correlation coefficient $(0.40-0.70)$ between FAQLQ-CF and FAIM revealed construct validity, and a low correlation coefficient $(0.10-0.30)$ between FAQLQ-CF and PedsQLTM convergent validity (Flokstra-de Blok et al., 2009).

\section{Translation and culture adaptation}

Two independent Greek translators produced forward translations and one other bilingual translator backward translation according to WHO guidelines.

To ensure face validity, this version was given to nine 8-12 year old food allergy children to complete and declare item understanding. Children had some difficulties grasping the meaning of questions 10 (we added the auxiliary text That is, how much it bothers you that you have to think whether you can eat a food that you may be allergic to) and 22 (we changed the phrase never get rid of food allergy to the more easily understandable might never go away). The question How often do you eat out? was added to access discriminant validity. A cultural adaptation issue had occurred with the third question of FAIM; we changed the phrase will die with lose your life.

\section{Validation}

Exploratory factor analysis, applying principal components analysis, was implemented in order to uncover the underlying structure of the relatively large set of FAQLQ-CF items, i.e., the underlying relationships between them, in our dataset (construct validity). Confirmatory factor analysis, via structural equation modeling using maximum likelihood estimation procedures with the relatively unaffected by sample size Tucker-Lewis Index (TLI) and Bollen's Incremental Fit Index (IFI) (Bollen, 1990; Gerbing \& Anderson, 1993; Hu \& Bentler, 1995; Marsh, Balla \& McDonald, 1988), was also implemented in order to test the originally proposed four-factor structure with our data (McDonald, 1978).

The internal consistency of the instrument was assessed using Cronbach's alpha coefficient (the total scale alpha should be at least 0.70 to be acceptable, 0.80 to be good, and 0.90 to be excellent; (Clark \& Watson, 1995) and the subscale alphas should be greater than corresponding expected alphas calculated using the Spearman-Brown formula), and corrected item-total correlations (Pearson's $r$ for each subscale should be $>0.300$, otherwise the item should be removed from the questionnaire) (Field, 2011; Lyrakos, Vini, Aslani, \& Drosou-Servou 2012; Norusis \& SPSS Inc, 1997).

The tool's ability to differentiate among children with various QoL levels and among various components of the QoL was checked, as well as between children who reported anaphylaxis and those who did not, as the original study did. Anaphylaxis was defined as children who ever reported two or more of the following cardiovascular symptoms: dizziness, feeling your heart beat fast, loss of vision, inability to stand, light headedness, collapse, loss of consciousness/ passing out (Flokstra-de Blok et al., 2009). In addition it was checked to children who reported multiple food allergies, many different symptoms, severe reactions, epinephrine prescription, rarely eating out, and doing less things with others, compared with children who reported less food allergies, less symptoms etc. A difference greater than a minimal clinical importance difference (MCID) of 0.5 was considered clinically significant (Flokstra-de Blok et al., 2009; Jaeschke, Singer \& Guyatt, 1989; Juniper, Guyatt, Willan, \& Griffith, 1994). 


\section{Results}

The total and subscale FAQLQ-CF scores correlated significantly but moderately (Table 1), as expected, with the total FAIM, and with the five of the six individual FAIM questions. All but one FAQLQ-CF items correlated with at least two FAIM items. The total FAQLQ-CF and its original subscales correlated low with the total Peds $Q \mathrm{~L}^{\mathrm{TM}}$ and moderately with one of its subscales (emotional functioning).

The factor analysis resulted in four factors that made the most sense, explaining $50 \%$ of the variance, partly confirmed the original factors (Table 2). An expert panel (ZM, ID, GL, NP) reviewed the new four factors. They could be allergen avoidance (AA, F1) and dietary restrictions (DR, F4) as in the original study, and two new ones whose names could be emotional functioning (EF, F2) and risk impact (RI, F3). All the factors had strong loadings from 0.410 to 0.768 (AA, 0.7280.499; EF, 0.704-0.450; RI, 0.768-0.410 and DR, 0.735-0.427).

Cronbach alphas were 0.905 for the total Greek FAQLQ-CF (Table 3) and greater than expected for its subscales (except for the RAE where it was slightly less, 0.631 vs 0.665 ). Corrected item total correlations were between 0.387 and 0.709 for the total Greek FAQLQ-CF (Table 3) and greater than 0.300 for its subscales (except for the RAE where it was between 0.243 and 0.463 ). Total FAIM alpha was 0.653 (acceptable), raised to 0.703 (good) after the omission of item 5 (IM1), the corrected item total correlation of which was only 0.029 , indicating that this item might be removed.

FAQLQ-CF discriminated well between children who reported different QoL levels (Supplementary Figure F1) and different QoL deterioration reasons (Supplementary Figure F2). Children's QoL ranged from 0.67 (11\%) in the negative $0-6$ scale (reversely $89 \%$ of the best quality) to 4.95 ( $83 \%$; reversely $17 \%$ of the best). QoL deteriorating reasons ranged $32-80 \%$ (questions 4,14 ). Children who reported more than moderately affected in doing things with others were clinically and statistically more impacted than those who reported less than moderately affected (total FAQLQ-CF score 3.553 vs 2.570 , difference $=0.98>$ MID; $\mathrm{P}<0.001$; Supplementary Table S2). The same result was found for feeling angry; difference $=0.592>\mathrm{MID}, \mathrm{P}=0.003$ ). There was an almost clinically and statistically significant difference in total FAQLQ-CF mean score between children who reported more than fairly chance to die and children eating out compared to those who reported less than fairly. The FAQLQ-CF score did not differ between children who reported anaphylaxis or various combinations of cardio-respiratory symptoms and children who did not. Things done with others was the only variable

Table 1. Spearman's correlation coefficient of the total Food Allergy Quality of life Questionnaire-Child Form (FAQLQ-CF) score and its domains and questions with the Food Allergy Independent Measure (FAIM) questions and total and with the Pediatric Quality of Life Inventory (PedsQL ${ }^{\mathrm{TM}}$ ) domains and total.

\begin{tabular}{|c|c|c|c|c|c|c|c|c|c|c|c|c|}
\hline \multirow[t]{2}{*}{ FAQLQ-CF } & \multirow[b]{2}{*}{ E01 } & \multicolumn{5}{|c|}{ FAIM questions and total } & \multicolumn{6}{|c|}{ PedsQLTM domains (subscales) and total } \\
\hline & & EO2 & EO3 & E04 & IM1 & IM2 & Total & PF & EF & SF & ScF & Total \\
\hline Total & $0.346^{* *}$ & $0.296^{*}$ & $0.308^{* *}$ & $0.413^{* *}$ & 0.057 & $0.486^{* *}$ & $0.509^{* *}$ & -0.138 & -0.320 & -0.082 & -0.136 & -0.224 \\
\hline Allergen avoidance & $0.355^{* *}$ & $0.256^{* *}$ & $0.268^{* *}$ & $0.334^{* *}$ & -0.033 & $0.389 * *$ & $0.426^{* *}$ & -0.092 & -0.336 & -0.128 & -0.108 & -0.217 \\
\hline 4 read labels & $0.221^{*}$ & $0.219^{*}$ & 0.054 & $0.218^{*}$ & 0.010 & $0.406^{* *}$ & $0.306^{* *}$ & & & & & \\
\hline 6 stay for a meal & $0.272^{* *}$ & 0.147 & $0.299 * *$ & $0.204^{*}$ & 0.131 & $0.327^{* *}$ & $0.371^{* *}$ & & & & & \\
\hline 7 try fewer things & $0.257^{* *}$ & 0.047 & 0.062 & 0.158 & 0.133 & $0.202^{*}$ & $0.223^{*}$ & & & & & \\
\hline 8 tell beforehand & 0.154 & 0.136 & 0.154 & 0.180 & -0.124 & $0.256^{* *}$ & $0.204^{*}$ & & & & & \\
\hline 9 check yourself & $0.266^{* *}$ & $0.243^{*}$ & $0.291 * *$ & $0.333^{* *}$ & -0.144 & 0.158 & $0.337^{* *}$ & & & & & \\
\hline 10 hesitate eating & $0.337^{* *}$ & $0.301^{* *}$ & $0.313^{* *}$ & 0.151 & -0.062 & $0.273^{* *}$ & $0.357^{* *}$ & & & & & \\
\hline 15 explain around & 0.097 & 0.004 & -0.005 & $0.267^{* *}$ & -0.059 & $0.214^{*}$ & 0.133 & & & & & \\
\hline Risk accidental exposure & $0.347^{* *}$ & $0.205^{*}$ & $0.261^{* *}$ & $0.264^{* *}$ & 0.009 & $0.409 * *$ & $0.395^{* *}$ & -0.088 & -0.301 & -0.081 & -0.151 & -0.224 \\
\hline 11 touching foods & $0.297^{* *}$ & $0.216^{*}$ & 0.135 & 0.082 & -0.097 & 0.178 & $0.196^{*}$ & & & & & \\
\hline 13 ingredient change & $0.261^{* *}$ & $0.231^{*}$ & 0.179 & $0.252^{* *}$ & -0.061 & $0.393^{* *}$ & $0.321^{* *}$ & & & & & \\
\hline 14 label traces of ... & $0.198 *$ & 0.019 & 0.109 & 0.112 & 0.034 & $0.280^{* *}$ & $0.199 *$ & & & & & \\
\hline 16 people forget & $0.189^{*}$ & -0.039 & 0.167 & 0.022 & 0.065 & $0.228 *$ & 0.177 & & & & & \\
\hline 17 others can eat & 0.168 & $0.254^{* *}$ & 0.187 & $0.353^{* *}$ & 0.092 & $0.289 * *$ & $0.351^{* *}$ & & & & & \\
\hline Emotional impact & $0.277^{* *}$ & $0.332^{* *}$ & $0.382^{* *}$ & $0.438^{* *}$ & 0.100 & $0.409 * *$ & $0.519 * *$ & -0.068 & -0.232 & -0.039 & -0.096 & -0.154 \\
\hline 19 allergic reaction? & $0.239^{*}$ & $0.348^{* *}$ & $0.276^{* *}$ & $0.283^{* *}$ & 0.044 & $0.230^{*}$ & $0.373^{* *}$ & & & & & \\
\hline 20 eating wrong & 0.100 & $0.316^{* *}$ & $0.272^{* *}$ & $0.284^{* *}$ & 0.034 & $0.232^{*}$ & $0.325^{* *}$ & & & & & \\
\hline 21 never before & $0.200^{*}$ & 0.142 & $0.225^{*}$ & 0.169 & $0.216^{*}$ & $0.297^{* *}$ & $0.336^{* *}$ & & & & & \\
\hline 22 never get rid & $0.273^{* *}$ & $0.270^{* *}$ & $0.253^{* *}$ & $0.318^{* *}$ & -0.024 & $0.322 * *$ & $0.376^{* *}$ & & & & & \\
\hline 23 not taking account & $0.199 *$ & $0.248^{* *}$ & 0.155 & $0.298^{* *}$ & 0.103 & $0.321^{* *}$ & $0.338^{* *}$ & & & & & \\
\hline 24 have food allergy & $0.254^{* *}$ & $0.228^{*}$ & $0.318^{* *}$ & $0.426^{* *}$ & 0.104 & $0.332 * *$ & $0.450 * *$ & & & & & \\
\hline Dietary restriction & 0.166 & $0.226^{*}$ & $0.196^{*}$ & $0.377^{* *}$ & 0.185 & $0.456^{* *}$ & $0.419 * *$ & $-0.245^{*}$ & $-0.269 *$ & $-0.061^{*}$ & $-0.132 *$ & $-0.226^{*}$ \\
\hline 1 always watch & 0.072 & 0.141 & 0.052 & $0.200^{*}$ & 0.152 & $0.215^{*}$ & $0.190 *$ & & & & & \\
\hline 2 eating fewer things & 0.121 & $0.201 *$ & 0.126 & $0.269 * *$ & 0.139 & $0.299 * *$ & $0.299 * *$ & & & & & \\
\hline 3 limited in buying & 0.071 & 0.128 & 0.104 & $0.202 *$ & $0.266^{* *}$ & $0.302^{* *}$ & $0.282^{* *}$ & & & & & \\
\hline 5 refuse food & 0.178 & 0.183 & 0.178 & $0.280^{* *}$ & 0.041 & $0.307^{* *}$ & $0.313^{* *}$ & & & & & \\
\hline 12 don't get treats & 0.115 & 0.111 & 0.111 & $0.329 * *$ & $0.217^{*}$ & $0.404^{* *}$ & $0.326^{* *}$ & & & & & \\
\hline 18 don't know taste & 0.086 & 0.084 & 0.065 & $0.187^{*}$ & 0.000 & $0.288^{* *}$ & 0.184 & & & & & \\
\hline
\end{tabular}

Correlation is significant at the *0.05\%*0.01 level (2-tailed). We also performed 1-tailed analysis and the results are very similar; all correlations remain the same and only 32 significant at the 0.05 level values became significant at the 0.01 level (see Supplementary Table S3). EO: child's food allergy expectation outcome. IM: independent measure. EO1: How big do you think the chance is that you will accidentally eat something to which you are allergic? EO2: How big do you think the chance is that you will have a severe reaction if you accidentally eat something to which you are allergic? EO3: How big do you think the chance is that you will die if you accidentally eat something to which you are allergic? EO4: How big do you think the chance is that you can not do the right things for your allergic reaction, should you accidentally eat something to which you are allergic? IM 1: How many foods are you unable to eat because of your food allergy? IM 2: How much does your food allergy affect things you do with others? PF: physical functioning, EF: emotional functioning, SF: social functioning, ScF: school functioning. 
Table 2. Confirmatory factor analysis: loadings (>0.4) in each of our four factors (F1 to F4) for each question (Q); the original factor (OF) for each question is also given.

\begin{tabular}{|c|c|c|c|c|c|c|}
\hline Q & OF & F1 & F2 & F3 & F4 & Item \\
\hline 3 & $\mathrm{DR}$ & 0.735 & & & & Limited in buying \\
\hline 2 & DR & 0.726 & & & & Eating fewer things \\
\hline 18 & DR & 0.628 & & & & Refuse food \\
\hline 20 & DR & 0.591 & & & & Don't get treats \\
\hline 6 & $\mathrm{AA}$ & 0.545 & & & & Try fewer things \\
\hline 1 & DR & 0.427 & & & & Always watch \\
\hline 23 & EI & & 0.704 & & & Never get rid \\
\hline 22 & DR & & 0.681 & & & Don't know taste \\
\hline 13 & RAE & & 0.671 & & & Others can eat \\
\hline 24 & EI & 0.414 & 0.631 & & & Have food allergy \\
\hline 17 & EI & & 0.583 & & & Not taking account \\
\hline 5 & $\mathrm{AA}$ & & 0.492 & & & Stay for a meal \\
\hline 10 & RAE & & 0.450 & & & Ingredient change \\
\hline 15 & EI & & & 0.768 & & Eating wrong \\
\hline 14 & EI & & & 0.747 & & Allergic reaction \\
\hline 9 & RAE & & & 0.590 & & Touching foods \\
\hline 16 & EI & & & 0.578 & & Never eaten \\
\hline 21 & RAE & & & 0.496 & & People forget \\
\hline 8 & $\mathrm{AA}$ & & & 0.492 & & Hesitate eating \\
\hline 11 & RAE & & & 0.410 & & Label traces of ... \\
\hline 12 & $\mathrm{AA}$ & & & & 0.728 & Explain around \\
\hline 19 & $\mathrm{AA}$ & & & & 0.723 & Tell beforehand \\
\hline 4 & $\mathrm{AA}$ & 0.456 & & & 0.561 & Read labels \\
\hline 7 & $\mathrm{AA}$ & & & & 0.499 & Check yourself \\
\hline
\end{tabular}

Extraction method: principal component analysis. Rotation method: Varimax with Kaiser normalization. Rotation converged in 6 iterations for CFA and in 18 for EFA. Extract: number of factors 4 for CFA, Eigenvalues over 1 for EFA. Coefficient display format: sorted by size; suppress absolute value less than 0.4 . The EI 24 and AA 4 were the only items with loading higher than 0.400 in two different factors.

Table 3. Cronbach's alpha and corrected item-total correlation for Food Allergy Quality of life Questionnaire-Child Form (FAQLQ$\mathrm{CF})$, Pediatric Quality of Life Inventory (Peds $\left.Q L^{\mathrm{TM}}\right)$, and Food Allergy Independent Measure (FAIM).

\begin{tabular}{|c|c|c|c|c|c|}
\hline \multirow[t]{2}{*}{ Scale/Subscale } & \multirow[t]{2}{*}{ It } & \multicolumn{3}{|c|}{ Cronbach's alpha $(\alpha)$} & \multirow[t]{2}{*}{ Corrected item-total correlation* } \\
\hline & & Obs & Exp* & Orig & \\
\hline FAQLQ-CF (total scale) & 24 & 0.905 & & 0.94 & $0.387-0.709$ \\
\hline Allergen avoidance & 7 & 0.775 & 0.735 & 0.88 & $0.413-0.601$ \\
\hline Risk of accidental exposure & 5 & $0.631^{\dagger}$ & 0.665 & 0.82 & $0.243-0.463$ \\
\hline Emotional impact & 6 & 0.758 & 0.705 & 0.87 & $0.428-0.592$ \\
\hline Dietary restrictions & 6 & 0.747 & 0.705 & 0.83 & $0.353-0.587$ \\
\hline Factor 1 (DR) & 6 & 0.775 & 0.705 & & $0.419-0.602$ \\
\hline Factor 2 (EF) & 7 & 0.826 & 0.735 & & $0.511-0.711$ \\
\hline Factor 3 (RI) & 7 & 0.764 & 0.735 & & $0.443-0.601$ \\
\hline Factor $4(\mathrm{AA})$ & 4 & 0.713 & 0.615 & & $0.448-0.623$ \\
\hline First half (questions 1-12) & 12 & 0.845 & 0.827 & & $0.349-0.641$ \\
\hline Second half (questions 13-24) & 12 & 0.837 & 0.827 & & $0.405-0.684$ \\
\hline Odd (questions $1,3,5, \ldots, 23$ ) & 12 & 0.805 & 0.827 & & $0.351-0.542$ \\
\hline Even (questions $2,4,6, \ldots, 24$ ) & 12 & 0.836 & 0.827 & & $0.363-0.684$ \\
\hline PedsQL ${ }^{\mathrm{TM}}$ (total scale) & 23 & $0.887^{\circ}$ & & $>0.70^{\circ 0}$ & $0.216-0.684$ \\
\hline Physical functioning & 8 & $0.775^{\circ}$ & 0.732 & $0.65^{\circ \circ}$ & $0.336-0.636$ \\
\hline Emotional functioning & 5 & $0.734^{\circ}$ & 0.631 & $>0.70^{\circ \circ}$ & $0.392-0.623$ \\
\hline Social functioning & 5 & 0.809 & 0.631 & $>0.70^{\circ \circ}$ & $0.534-0.661$ \\
\hline School functioning & 5 & $0.717^{\circ}$ & 0.631 & $>0.70^{\circ \circ}$ & $0.290-0.682$ \\
\hline FAIM (total scale) & 6 & $0.653^{\circ}$ & & & $0.029-0.601$ \\
\hline $\mathrm{OE}$ & 4 & 0.706 & 0.616 & & $0.433-0.580$ \\
\hline $\mathrm{IM}$ & 2 & 0.194 & 0.445 & & negative - negative \\
\hline
\end{tabular}

It, number of items; Obs, observed (in italics where obs<exp); Exp, expected; Orig, original, i.e., Flokstra et al. (2009) for FAQLQ-CF, Gkoltsiou et al. (2008) for PedsQL ${ }^{\mathrm{TM}}$, and Van der Velde et al. (2010) for FAIM. *Expected subscale alphas were calculated using the Spearman-Brown formula $\alpha_{\text {subsale }}=k \alpha_{\text {scale }} /\left(1+(\mathrm{k}-1) \alpha_{\text {scale }}\right)$, where $\mathrm{k}$ is the number of items of the subscale divided by the number of items of the overall scale. 1,10 **Range of Pearson correlation coefficients $\mathrm{r}$. For example, in the first line, the $24 \mathrm{r}$ coefficients for the FAQLQ-CF (total scale) range 0.387 (for the question 11 «How troublesome is it, because of your food allergy, that the label states: "May contain traces of...."? ») to 0.709 (for the question 24 «How disappointed do you feel because you have a food allergy?»). Similarly the $23 \mathrm{r}$ coefficients for the PedsQL $\mathrm{L}^{\mathrm{TM}}$ (total scale) range 0.216 to 0.684 . And the $6 \mathrm{r}$ coefficients for the FAIM (total scale) range 0.029 (for the question 5 «How many foods are you unable to eat because of your food allergy?») to 0.601 (for the question 2 «How big do you think the chance is that you will have a severe reaction if you accidentally eat something to which you are allergic?»). ${ }^{\circ} 0.631$ increased to 0.644 (greater than expected 0.615 ) if item 17 was deleted; 0.887 to 0.890 if item 11 and to 0.888 if item 23 was deleted; 0.775 to 0.788 if item 7 was deleted; 0.734 to 0.736 if item 11 was deleted; 0.717 to 0.730 if item 22 was deleted; and 0.653 to 0.703 if item 5 was deleted; no other observed alpha increased after deletion of any of the items for any of the other scales or subscales. ${ }^{\circ o " A l l ~ s e l f-r e p o r t ~ a n d ~ p r o x y-r e p o r t ~ s c a l e s ~ o f ~ P e d s Q L ~}{ }^{\mathrm{TM}} 4.0$, except for physical functioning self-report $(\mathrm{a}=0.65)$, exceeded the minimum reliability standard of $0.70 " .28$ 
that affected clinically and statistically the mean FAIM-OE score (the difference disappeared if the IM1 question was added), and the mean PedsQ $\mathrm{L}^{\mathrm{TM}}$ score. The statistically $(\mathrm{P}=0.035)$ significantly worse mean PedsQL ${ }^{\mathrm{TM}}$ score in older children was also clinically significant [absolute $(-0.18)>0.1744=$ MID] .

\section{Discussion}

Content validity, the extent to which a measure represents all facets of a given social construct, perhaps the most important thing of a questionnaire, was addressed by the original study. Thus, we focused on questionnaire's translation and cultural adaptation in Greek.

Construct validity refers to whether the questionnaire is measuring what it is supposed to measure and can be assessed by correlating a new questionnaire with an independent measure which reflects disease severity (van der Velde et al., 2010). The significant correlation between FAQLQ-CF and FAIM assures construct validity, fits with Floskra de Blok and Wassenberg, and demonstrates that Greek FAQLQCF is measuring the food allergy affected QoL (Flokstra-de Blok et al., 2009; Wassenberg et al., 2011). As in the original study, we supplemented statistical factoring by face validity (Flokstra-de Blok et al., 2009).

Cronbach alpha for the total Greek FAQLQ-CF (0.905) indicates an excellent reliability (Fayers \& Machin, 2000). Tavakol and Dennick argue that an alpha $>0.90$ may suggest redundancies and show that the tool's length should be shortened (Tavakol \& Dennick, 2011). No alpha if item deleted was greater than without deletion, an indication of no redundancies. Item-total Pearson's correlations showed that all items are well related ( $r>0.300)$, an indication of no need for any item to be removed (except an item in RA with $r=0.243$, considered by the expert panel as important for the questionnaire).

The questionnaire discriminates between various QoL levels and various QoL components. Thus, it could serve as a helpful additional tool, as a good first step, for clinicians to manage children's allergy. It also discriminates well between children who reported more than and less than moderately affected in doing things with others. There was no difference according to eating out, chance to die, feeling angry and age. Children who reported anaphylaxis did not differ with children who did not report anaphylaxis, as also Floskra de Blok et al. found (Flokstra-de Blok et al., 2009). One possible explanation could be that the children who reported anaphylaxis were only four; however we found no difference after broadening the anaphylaxis definition. Also there was no difference according to one or multiple food allergies, as Wassenberg et al and Floskra de Blok et al found (Flokstra-de Blok et al, 2009; Wassenberg et al, 2011).

Total FAQLQ-CF score correlated with the total PedsQL $\mathrm{L}^{\mathrm{TM}}$ and with one of its four subscales, the emotional functioning. Surprisingly, the two emotional subscales, FAQLQ-CF emotional impact and PedsQL ${ }^{T M}$ emotional functioning had the lowest correlation (rho=0.232) and less significance; we have no explanation for this. The presence of some correlation between FAQLQ-CF and PedsQL ${ }^{\mathrm{TM}}$ indicates that both are measuring constructs partly related (i.e. convergent validity) (Flokstrade Blok et al., 2009). On the other hand, the (as expected) low correlations indicate that the generic PedsQL $\mathrm{L}^{\mathrm{TM}}$ is not as sensitive as the disease-specific FAQLQ-CF (i.e. discriminant validity) (Flokstra-de Blok \& Dubois, 2009).

\section{Limitations}

The data were collected by telephone. The phone interview is quick, convenient and can effectively cover all southern Greece and the islands at the lowest cost. However it needs more caution to time limi- tations and intra-interviewer variability. To reduce time limitations all phone calls were made at a predetermined time after consultation of the interviewer and the parent, and we did our best to keep intra-interviewer variability to a minimum. Future research could clarify whether our final product can also be used for face-to-face, paper or electronic administration.

The study had a sample almost at the lowest numerical limit needed for factor analysis (110 instead 120); though the difference could reasonably be considered negligible, as the sampling adequacy diagnostics found (Stevens, 2002), and though that ours was bigger than the other validation studies sample (79 and 32 respectively), (Flokstra-De Blok et al., 2009; Wassenberg et al, 2011). we used factor analysis with the relatively unaffected by sample size TLI and IFI (Bollen, 1990; Gerbing \& Anderson, 1993; Hu \& Bentler, 1995; Marsh, Balla \& McDonald, 1988 ). To check discriminant ability the questionnaire should be administered to known groups with good and poor QoL; we didn't have such groups and reached to conclusions indirectly using reasonable hypotheses, as the original and translation studies also did (Flokstra-de Blok et al., 2009; Wassenberg et al., 2011). Finally, we didn't check tool's responsiveness; its good discriminant ability is an indirect evidence of it (Fayers \& Machin, 2000).

\section{Conclusions}

Concluding, this study showed that the Greek FAQLQ-CF, the European standard questionnaire on food allergic children, has satisfactory validity, reliability, and discriminant ability. The tool could help clinicians to detect children in need for immediate care and children's deterioration reasons.

\section{References}

Bollen, K.A. (1990). Overall fit in covariance structure models: two types of sample size effects. Psychological Bulletin, 107(2), 256 259. doi:10.1037/0033-2909.107.2.256.

Clark, L.A., \& Watson, D. (1995). Constructing validity: basic issues in objective scale development. Psychological Assessment, 7, 309-319. doi:10.1037/1040-3590.7.3.309.

Factor, J.M., Mendelson, L., Lee, J., Nouman, G., \& Lester, M.R. (2012). Effect of oral immunotherapy to peanut on food-specific quality of life. Annals of allergy, asthma \& immunology:official publication of the American College of Allergy, Asthma, \& Immunology, 109, 348352. doi: 10.1016/j.anai.2012.08.015.

Fayers, P.M., \& Machin, D. (2000). Quality of life: assessment, analysis and interpretation. Hoboken: John Willey \& Sons.

Field, A. (2011). Discovering statistics using SPSS (4rd ed.). London, Sage.

Flokstra-de Blok, B., \& Dubois, A. (2009). Quality of life in food allergy: valid scales for children and adults. Current Opinion in Allergy and Clinical Immunology, 9, 214-221. doi: 10.1097/ACI.0b013 e32832aa59f.

Flokstra-de Blok, B.M., \& Dubois, A.E. (2012). Quality of life measures for food allergy. Clinical and Experimental Allergy: Journal of the British Society for Allergy and Clinical Immunology, 42, 1014-1020. doi: 10.1111/j.1365-2222.2011.03927.x.

Flokstra-de Blok, B., DunnGalvin, A., Vlieg-Boerstra, B.J., Oude Elberink, J.N., Duiverman, E.J., Hourihane, J.O., \& Dubois, A.E. (2009). Development and validation of a self-administered Food Allergy Quality of Life Questionnaire for children. Clinical and 
Experimental Allergy: Journal of the British Society for Allergy and Clinical Immunology, 39, 127-137. doi: 10.1111/j.13652222.2008.03120.x.

Flokstra-de Blok, B.M., van der Velde, J.L., Vlieg-Boerstra, B.J., Oude Elberink, J.N., DunnGalvin, A., Hourihane, J.0., ..., Dubois, A.E. (2010). Health-related quality of life of food allergic patients measured with generic and disease-specific questionnaires. Allergy, 65, 1031-103. doi: 10.1111/j.1398-9995.2009.02304.x

Gerbing, D.W., \& Anderson, J.C. (1993). Monte Carlo evaluations of goodness-of-fit indices for structural equation models. In: K.A. Bollen, \& J.S. Long (Eds.), Testing structural equation models. Newbury Park, CA: Sage.

Gkoltsiou, K., Dimitrakaki, C., Tzavara, C., Papaevangelou, V., Varni, J.W., \& Tountas, Y. (2008). Measuring health-related quality of life in Greek children: psychometric properties of the Greek version of the Pediatric Quality of Life InventoryTM 4.0 Generic Core Scales. Quality of life research: an international journal of quality of life aspects of treatment, care and rehabilitation, 17, 299-305. doi: 10.1007/s11136-007-9294-1.

Gupta, R.S., Springston, E.E., Warrier, M.R., Smith, B., Kumar, R., Pongracic, J., \& Holl, J.L. (2011). The prevalence, severity, and distribution of childhood food allergy in the United States. Pediatrics, 128, 9-17. doi:10.1001/jamapediatrics.2013.2376.

Guyatt, G., Feeny, D., \& Patrick, D. (1993). Measuring health-related quality of life. Annals of Internal Medicine, 118 , 622-629. doi:10.7326/0003-4819-118-8-199304150-00009.

Hu, L.T., \& Bentler, P. (1995). Evaluating model fit. In R.H. Hoyle (Ed.), Structural Equation Modeling. Concepts, issues, and applications. Newbury: Sage. pp 76-79.

Jaeschke, R., Singer, J., \& Guyatt, G.H. (1989). Measurement of health status. Ascertaining the minimal clinically important difference. Controlled Clinical Trials, 10, 407-15. doi: 10.1016/01972456(89)90005-6.

Juniper, E.F., Guyatt, G.H., Willan, A., \& Griffith, L.E. (1994). Determining a minimal important change in a disease-specific quality of life questionnaire. Journal of Clinical Epidemiology, 47(1), 81-87. doi: 10.1016/0895-4356(94)90036-1.

Lyrakos, G.N., Vini, D., Aslani, H., \& Drosou-Servou, M. (2012). Psychometric properties of the Specific Thalassemia Quality of Life Instrument for adults. Patient preference and adherence, 6, 477-497. doi: 10.2147/PPA.S30763.

Marsh, H.W., Balla, J.R., \& McDonald, R.P. (1988). Goodness of fit indexes in confirmatory factor analysis: the effect of sample size. Psychological Bulletin, 103, 391-410. doi: 10.1037/00332909.103.3.391.

McDonald, R.P. (1978). A simple comprehensive model for the analysis of covariance structures. British Journal of Mathematical and Statistical Psychology, 31, 59-72. doi: 10.1111/j.20448317.1978.tb00573.x

Mills, E., Mackie, A.R., Burney, P., Beyer, K., Frewer, L., Madsen, C., ..., van Ree, R. (2007). The prevalence, cost and basis of food allergy across Europe. Allergy, 62, 717-722. doi: 10.1111/j.1398- 9995.2009.02046.x

Norusis, M.J., SPSS Inc. (1997). SPSS Professional Statistics ${ }^{\mathrm{TM}} 7.5$. Chapter 13 Measuring scales: reliability analysis examples. Chicago: SPSS Inc. 103-111.

Rona, R.J., Keil, T., Summers, C., Gislason, D., Zuidmeer, L., Sodergren, E., ..., Madsen, C. (2007). The prevalence of food allergy: a metaanalysis. Journal of Allergy and Clinical Immunology, 120, 638-646. doi: 10.1016/j.jaci.2007.05.026.

Stevens, J. (2002). Applied Multivariate Statistics for the Social Sciences. 4th ed. Mahwaw, New Jersey: Lawrence Erlbaum Associates Inc.

Tavakol, M., \& Dennick, R. (2011). Making sense of Cronbach's alpha. Interantional Journal of Medical Education, 2, 53-55. doi: 10.5116/ijme.4dfb.8dfd.

Van der Velde, J.L., Flokstra-de Blok, B.M., de Groot, H., Oude-Elberink, J.N., Kerkhof, M., Duiverman, E.J., \& Dubois, A.E. (2012). Food allergy-related quality of life after double-blind, placebo-controlled food challenges in adults, adolescents, and children. Journal of Allergy and Clinical Immunology, 130(5), 1136-1143. doi: 10.1016/j.jaci.2012.05.037.

Van Der Velde, J., Flokstra-de Blok, B.M., DunnGalvin, A., Hourihane, J.O., Duiverman, E.J., \& Dubois, A.E. (2011). Parents report better health-related quality of life for their food-allergic children than children themselves. Clinical and experimental allergy: journal of the British Society for Allergy and Clinical Immunology, 41, 14311439. doi: 10.1111/j.1365-2222.2011.03753.x.

Van der Velde, J.L., Flokstra-de Blok, B.M., Vlieg-Boerstra, B.J., Oude Elberink, J.N., DunnGalvin, A., Hourihane, J.O., ..., Dubois, A.E. (2010). Development, validity and reliability of the food allergy independent measure (FAIM). Allergy, 65, 630-635. doi: 10.1111/j.1398-9995.2009.02216.x.

Varni, J., Seid, M., \& Kurtin, P. (2001). The PedsQL ${ }^{\text {TM }}$ 4.0. Reliability and validity of the Pediatric Quality of Life Inventory TM Version 4.0 Generic Core Scales in Healthy and patient populations. Medical Care, 39, 800-812. doi: 10.1097/00005650-20010800000006 .

Wassenberg, J., Cochard, M., DunnGalvin, A., Ballabeni, P., Flokstra-de Blok, B.M., Newman, C.J., ..., Eigenmann, P.A. (2012). Parent perceived quality of life is age-dependent in children with food allergy. Pediatric allergy and immunology: official publication of the European Society of Pediatric Allergy and Immunology, 23, 412-419. doi: 10.1111/j.1399-3038.2012.01310.x.

Wassenberg, J., Cochard, M.M., DunnGalvin, A., de Blok, B.M.J., Hofer, M., \& Eigenmann, P.A. (2011). Qualité de vie chez l'enfant avec allergie alimentaire: validation de la version française des questionnaires spécifiques de qualité de vie. Revue Française d'Allergologie, 51, 437-438. doi: 10.1016/j.reval.2011.02.024

WHO. (1993). Measurement of Quality of life in children. Geneva: World Health Organization.

WHO. Process of translation and adaptation of instruments. Retrieved from: http://www.who.int/substance_abuse/research_tools/translation/en/ 